\title{
Nursery Cities: \\ Urban Diversity, Process Innovation, and the Life Cycle of Products
}

\author{
By Gilles Duranton and Diego PugA*
}

\begin{abstract}
This paper develops microfoundations for the role that diversified cities play in fostering innovation. A simple model of process innovation is proposed, where firms learn about their ideal production process by making prototypes. We build around this a dynamic general-equilibrium model, and derive conditions under which diversified and specialized cities coexist. New products are developed in diversified cities, trying processes borrowed from different activities. On finding their ideal process, firms switch to mass production and relocate to specialized cities where production costs are lower. We find strong evidence of this pattern in establishment relocations across French employment areas 1993-1996. (JEL R30, O31, D83)
\end{abstract}

A key issue in urban development, as highlighted by the writings of Jane Jacobs (1969), is the role that diversified metropolitan areas play in fostering innovation. To date, no one has specified the microfoundations for such a role. Most models of urban systems leave no role to diversity. Those that do simply assume that local diversity is essential to the static efficiency

\footnotetext{
* Duranton: Department of Geography and Environment, London School of Economics, Houghton Street, London WC2A 2AE, United Kingdom (e-mail: g.duranton@1se.ac.uk; website: http://cep.lse.ac.uk/ duranton); Puga: Department of Economics, University of Toronto, 150 St. George Street, Toronto, Ontario M5S 3G7, Canada (e-mail: d.puga@utoronto.ca; website: http://dpuga.economics. utoronto.ca). We are very grateful to Frédéric Lainé and PierrePhilippe Combes for kindly providing us with the data on, respectively, plant relocations and sectoral composition of employment for French employment areas; also to Vernon Henderson for very helpful discussions, and to Nancy Gallini, Martin Osborne, and Dan Trefler for detailed comments on earlier drafts of this paper. We have also benefited from comments and suggestions by Richard Baldwin, Jim Brander, Rikard Forslid, Elhanan Helpman, Boyan Jovanovic, Maureen Kilkenny, Tomoya Mori, Nate Rosenberg, Barbara Spencer, Manuel Trajtenberg, as well as other participants at various seminars and three anonymous referees. Puga gratefully acknowledges financial support from the Canadian Institute for Advanced Research, the Social Sciences and Humanities Research Council of Canada, and from the Connaught Fund of the University of Toronto.
}

of certain activities. ${ }^{1}$ In this paper we develop microfoundations for the role that diversified urban environments play in facilitating search and experimentation in innovation. We combine this with a role for specialized environments in mass production. As a result, production relocates over the product life cycle from diversified to specialized cities - a pattern that we find is strongly supported by data on establishment relocations across French employment areas.

Our model builds on two standard static ingredients. First, the cost of using a given production process diminishes as more local firms use the same type of process because they can share intermediate suppliers. Second, urban crowding places a limit on city size. This combination of so-called "localization economies" with congestion costs creates static advantages to urban specialization. Most models of urban systems rely on variations of these two elements, and thus in equilibrium have only fully specialized cities (as in J. Vernon Henderson, 1987).

The main novelty of our framework is the simple model of process innovation that we develop and combine with those two more tra-

\footnotetext{
${ }^{1}$ See John M. Quigley (1998), Hesham M. AbdelRahman (2000), and Duranton and Puga (2000a) for detailed references and discussion.
} 
ditional ingredients. ${ }^{2}$ We start from the assumption that a young firm needs to experiment to realize its full potential - the entrepreneur may have a project, but may not know all the details of the product to be made, what components to use, or what kind of workers to hire. Of the many possible ways to implement this project, one is better than all others, and this ideal production process differs across firms. A firm can try to find its ideal production process by making a prototype with any one of the types of processes already used locally. If this process is not the right one, the firm can try different alternatives. Once a firm identifies its ideal process, which happens after using this process for a prototype or after exhausting all other possibilities, it can begin mass production of its product. The combination of this learning process that draws from local types of production processes with costly firm relocation creates dynamic advantages to urban diversity.

Firm turnover is introduced by having some firms randomly close down each period. Optimal investment then ensures they are replaced by new firms producing new products. In addition, migration makes workers in all cities equally well off. Finally, new cities can be created by competitive developers.

We solve this model, and derive a set of necessary and sufficient conditions for a configuration in which diversified and specialized cities coexist to be a steady state. We then show that the same conditions guarantee that this steady state is stable and unique. When diversified and specialized cities coexist, it is because each firm finds it in its best interest to locate in a diversified city while searching for its ideal process, and later to relocate to a specialized city where all firms are using the same type of process. Location in a diversified city during a firm's learning stage can be seen as an investment. It is costly because all firms impose con-

\footnotetext{
${ }^{2}$ A significant literature addresses firms' learning about their technology (see, in particular, Boyan Jovanovic [1982] and Jovanovic and Glenn M. MacDonald [1994]). However, previous modeling approaches cannot be easily embedded in a general-equilibrium model of a system of cities. Furthermore, they focus on firms learning in isolation or, in the strategic learning literature, on interactions based on imitations. The focus of this paper is instead on how the urban environment affects learning, and how firms can best choose their environment.
}

gestion costs on each other, but only those using the same type of process create cost-reducing localization economies. This results in comparatively higher production costs in diversified cities. However, bearing these higher costs can be worthwhile for firms in search of their ideal process because they expect to have to try a variety of processes before finding their ideal one, and a diversified city allows them to do so without costly relocation after each trial. In this sense, diversified cities act as a "nursery" for firms. Once a firm finds its ideal production process, it no longer benefits from being in a diverse environment. At this stage, if relocation is not too costly, the firm avoids the congestion imposed by the presence of firms using different types of processes by relocating to a city where all other firms share its specialization.

In contrast with the lack of theoretical work, there is a wealth of empirical work that studies the relative advantages of urban diversity and specialization. Our theoretical framework is consistent with the established empirical findings. For example, detailed micro evidence supports the benefits of diversity for innovation exhibited by our model. The work of Bennett Harrison et al. (1996) and Kelley and Susan Helper (1999) is of particular interest. They study the adoption of new production processes by individual establishments in the United States belonging to three-digit machine-making industries (ranging from heating equipment and plumbing fixtures to guided missiles and aircraft). They show that a diversity of local employment contributes significantly towards the adoption of new production processes, while narrow specialization hinders it. Similarly, Maryann P. Feldman and David B. Audretsch (1999) find that local diversity has a strong positive effect, and narrow specialization a negative one, on the development of new products reported by trade journals in the United States.

While providing microfoundations for the link between local diversity and innovation, our model also stresses the advantages of an urban system in which diversified and specialized cities coexist. This coexistence is a pervasive fact (see Henderson [1988] for evidence for Brazil, India, and the United States; Duncan Black and Henderson [1998] and Duranton and Puga [2000a] for additional U.S. evidence; Frédéric Lainé and Carole Rieu [1999] for evidence for 
France). The patterns of specialization and diversity are too marked to be random outcomes (Glenn Ellison and Edward L. Glaeser, 1997), and do not merely reflect comparative advantage (Ellison and Glaeser, 1999). Instead, such patterns appear to be to a large extent the result of economic interactions taking place both within and across sectors (Henderson, 1997a).

To assess the relative advantages of diversity and specialization, Glaeser et al. (1992) examine the evolution of urban employment patterns in U.S. cities. They find that diversity fosters urban employment growth. Pursuing this line of research, Henderson et al. (1995) show that, while urban diversity is indeed important for attracting new and innovative activities, a history of similar past specialization appears to matter more for retaining mature activities. Pierre-Philippe Combes (2000) finds similar results for France. Henderson (1999) takes a different approach, and looks at the evolution of productivity in manufacturing plants from hightech and machinery industries in the United States. He finds that same-sector specialization tends to have a positive effect on productivity. However, when he looks at employment changes, he finds once again that diversity is important to attract innovative activities. All of this is consistent with the predictions of our model, where firms learn about production processes that will boost their productivity in diversified cities, but then relocate to specialized cities to exploit such processes.

Cities have been shown to be very stable in terms both of their relative sizes (Jonathan Eaton and Zvi Eckstein, 1997; Black and Henderson, 1998), and of their sectoral composition (Sukkoo Kim, 1995; Guy Dumais et al., 1997; Henderson, 1997b, 1999). This stability is in contrast with a high rate of establishment turnover. Dumais et al. (1997) calculate that nearly three-fourths of U.S. plants existing in 1972 were closed by 1992 , and that more than onehalf of all U.S. manufacturing employees in 1992 worked in plants that did not exist in 1972. They also show that the opening of new plants tends to reduce the degree of agglomeration of particular sectors, suggesting that new plants are created in locations with below-average specialization in the corresponding sector. In France, according to the Institut National de la Statistique et des Etudes Economiques (INSEE,
1998) new establishments are also overwhelmingly located in more diversified areas. These patterns are entirely consistent with our model.

The model also assigns a central role to establishment relocations, and has a strong prediction for these: a tendency for production to relocate over the life cycle from diversified to specialized cities. A novel data set tracking establishment relocations across France allows us to directly validate this prediction.

This data set on establishment relocations was extracted from the Système Informatique pour le Répertoire des ENtreprises et de leurs Établissements (SIRENE) database of the INSEE. It contains the geographical origin and destination and the sectoral classification of every single establishment relocation that took place in France between 1993 and 1996 (see Lainé, 1998, for a detailed description). Only complete relocations are included in the data (that is to say, episodes in which the complete closure of an establishment is followed by the opening in a different location of an establishment owned by the same firm and performing the same full range of activities).

The geographical origin and destination of relocating establishments is identified at the level of employment areas (zones d'emplois). Continental France is fully covered by $341 \mathrm{em}-$ ployment areas, whose boundaries are defined on the basis of daily commuting patterns around urban centers. Relocating establishments are classified by sector according to level 36 of the Nomenclature d'Activités Française (NAF) classification of the INSEE. The 18 sectors we study cover all of manufacturing and business services, with the exception of postal services. To characterize French employment areas in terms of diversity and specialization, we use sectoral employment data for each employment area from the Enquête sur la Structure des Emplois (ESE) of the INSEE for December 1993. We measure the specialization of employment area $i$ in sector $j$ by the share of the corresponding NAF36 sector in local manufacturing and business-service employment, $s_{i}^{j}$. We measure the diversity of employment area $i$ by the inverse of a Herfindahl index of sectoral concentration of local employment, $1 / \sum_{j=1}^{85}\left(s_{i}^{j}\right)^{2}$, calculated in this case at a higher level of sectoral disaggregation given by the NAF85 classification. In order to identify employment areas 
Table 1-Establishment Relocations Across French Employment Areas 1993-1996

\begin{tabular}{lccc}
\hline \hline & $\begin{array}{c}\text { Percentage of } \\
\text { relocations from } \\
\text { diversified to } \\
\text { specialized areas }\end{array}$ & $\begin{array}{c}\text { Relocations } \\
\text { as a } \\
\text { percentage of } \\
\text { the stock }\end{array}$ & $\begin{array}{c}\text { Geographic } \\
\text { concentration }^{\text {c }}\end{array}$ \\
\hline R\&D & 93.0 & 8.1 & 0.023 \\
Pharmaceuticals and cosmetics & 88.3 & 6.4 & 0.020 \\
IT and consultancy services & 82.1 & 7.3 & 0.030 \\
Business services & 75.8 & 5.0 & 0.015 \\
Printing and publishing & 73.3 & 5.4 & 0.026 \\
Aerospace, rail and naval equipment & 71.6 & 3.3 & 0.026 \\
Electrical and electronic equipment & 69.1 & 4.2 & 0.011 \\
Motor vehicles & 62.5 & 2.7 & 0.020 \\
Electrical and electronic components & 60.9 & 5.9 & 0.007 \\
Textiles & 46.4 & 2.5 & 0.024 \\
Chemical, rubber and plastic products & 38.3 & 3.9 & 0.009 \\
Metal products and machinery & 37.6 & 3.2 & 0.005 \\
Clothing and leather & 36.3 & 3.4 & 0.013 \\
Food and beverages & 34.6 & 0.8 & 0.007 \\
Furniture and fixtures & 32.6 & 2.7 & 0.008 \\
Wood, lumber, pulp and paper & 30.6 & 1.7 & 0.009 \\
Primary metals & 30.0 & 2.5 & 0.009 \\
Nonmetallic mineral products & 27.3 & 2.0 & 0.012 \\
\hline Aggregate & 72.0 & 4.7 & \\
\hline
\end{tabular}

Source: Authors' calculations based on data from SIRENE and ESE.

${ }^{a}$ Percentage of all establishments relocating across employment areas that move from an area with above-median diversity to an area with above-median specialization.

${ }^{\mathrm{b}}$ Establishment relocations across employment areas as a percentage of the average number of establishments.

${ }^{\mathrm{c}}$ Ellison and Glaeser (1997) geographic concentration index.

which are particularly specialized in a given sector or particularly diversified, we normalize both measures by their median value for all employment areas. ${ }^{3}$

Table 1 presents the evidence. Looking first at the aggregate figures in the bottom row, we see that complete establishment relocations across French employment areas represented 4.7 percent of the average stock over this period $(29,358$ relocations from an average stock of 624,772 establishments). Strikingly, 72 percent of these relocations followed the pattern predicted by our model: they were from an area with above-median diversity to an area with

\footnotetext{
${ }^{3}$ By these measures, Lyon and Nantes are among France's most diversified areas, Chateaudun has the median diversity, while Lavelanet is both the least diversified and one of the most specialized areas (in textiles, which in 1993 accounted for 84 percent of local manufacturing and business-service employment).
}

above-median specialization in the corresponding sector. 4

Based on our model, more innovative and agglomerated sectors are likely to benefit the most from the advantages that diversity and specialization offer at different stages of the product cycle. As a result, we would expect establishments in more innovative and agglomerated activities to have a greater tendency to relocate from particularly diversified to particularly specialized areas. More traditional sectors, by contrast, will tend to experience fewer

\footnotetext{
${ }^{4}$ The relocation of production over a product's life cycle does not always require establishment relocations. Masahisa Fujita and Ryoichi Ishii (1998) show that the major Japanese electronic firms produce prototypes in trial plants that are located in metropolitan areas which are known to be particularly diversified. At the same time, their massproduction plants are almost always located in more specialized cities. Thus, our findings on establishment relocation patterns may just reflect the tip of the iceberg in the relocation of production over the life cycle.
} 
relocations and not necessarily with this nursery pattern. That is precisely what comes out of Table 1 when we split relocations by sector. R\&D, pharmaceuticals and cosmetics, IT and consultancy services, and business services are innovative sectors where, as reflected in the geographic concentration indices on the rightmost column, firms find it particularly beneficial to co-locate with firms in the same sector. These sectors have specially high relocation rates of between 5 and 8.1 percent. And between 75.8 and 93 percent of relocations in these sectors are from an area with above-median diversity to an area with above-median specialization. On the other hand, food and beverages, furniture and fixtures, wood, lumber, pulp and paper, primary metals, and nonmetallic mineral products are more traditional sectors which are not particularly agglomerated. These sectors have relocation rates of only between 0.8 and 2.7 percent, and less than 35 percent of those relocations are from an area with above-median diversity to an area with above-median specialization. Thus, in providing microfoundations for the role that diversified cities play in fostering innovation, our model helps us understand established stylized facts about urban systems, as well as previously unexplored features of firms' location and relocation patterns.

The remainder of the paper is structured as follows. We start by setting up the model (Section I) and deriving a number of basic results (Section II). These serve as the basis to derive a set of necessary and sufficient conditions for a configuration in which diversified and specialized cities coexist to be a steady state (Section III). We then show that the same conditions guarantee that this steady state is stable and unique (Section IV). We finish with some concluding remarks (Section V).

\section{The Model}

There are $N$ cities in the economy, where $N$ is endogenous, ${ }^{5}$ and a continuum $L$ of infinitely lived workers, each of which has one of $m$ possible discrete aptitudes. There are equal pro-

\footnotetext{
${ }^{5} \mathrm{~N}$ is assumed to be a continuous variable, but for simplicity we shall refer to it loosely as the "number" of cities. Similarly, we shall talk about the number and not the mass of firms even though there is a continuum of them.
}

portions of workers with each aptitude in the economy, but their distribution across cities is endogenously determined through migration. Let us index cities by subscript $i$ and worker aptitudes by superscript $j$ so that $l_{i}^{j}$ denotes the supply of labor with aptitude $j$ in city $i$. Time is discrete and indexed by $t$ (but to make notation less cumbersome, we only index variables by time when adding over different time periods).

\section{A. Technology}

Setting up a firm involves a one-off start-up cost, which enables the firm to start making trial products, referred to as prototypes. Perfectly competitive and frictionless capital markets provide firms with finance for their start-up cost and remunerate workers' savings. A firm may eventually engage in mass production, with lower production costs, but this involves using a certain "ideal" production process. This ideal process is firm specific and randomly drawn from a set of $m$ possible discrete processes, with equal probability for each. Each of the $m$ possible processes for each firm requires processspecific intermediate inputs from a local sector employing workers of a specific aptitude. Thus, through intermediate production, there is a oneto-one mapping between each firm's possible production processes and workers' aptitudes. We say that two production processes for different firms are of the same type if they require intermediates produced using workers with the same aptitude.

A newly created firm does not know its ideal production process, but it can find this by trying, one at a time, different processes in the production of prototypes. After producing a prototype with a certain process, the firm knows whether this process is its ideal one or not. Thus, in order to switch from prototype to mass production a firm needs to have produced a prototype with its ideal process first, or to have tried all of its $m$ possible processes except one. Furthermore, we allow for the possibility that a firm decides to stop searching before learning its ideal process.

Firms have an exogenous probability $\delta$ of closing down each period (we can think of this as being due to the death of a shadow entrepreneur). Firms also lose a period of production whenever they relocate from one city to another. Thus, the cost of firm relocation increases 
with the exogenous probability of closure $\delta$. This is because a higher value of $\delta$ makes firms discount future profits more relative to the profits forgone in the period lost in relocation.

The intermediates specific to each type of process are produced by a monopolistically competitive intermediate sector à la Wilfred J. Ethier (1982). As in Fujita (1988) and AbdelRahman and Fujita (1990), each such intermediate sector hires workers of aptitude $j$ and sells process-specific nontradable intermediate services to final-good firms using a process of type $j$. These differentiated services enter the production function of final-good producers with the same constant elasticity of substitution

$\frac{\varepsilon+1}{\varepsilon}$. Appendix A provides the equations describing this set up and shows that technology in prototypes can be summarized by the following cost function:

$$
\begin{gathered}
\qquad \stackrel{?}{C}_{i}^{j}(h)=Q_{i}^{j}{\stackrel{?}{x_{i}^{j}}(h),} \\
\text { where } Q_{i}^{j}=\left(l_{i}^{j}\right)^{-\varepsilon} w_{i}^{j}, \quad \varepsilon>0 .
\end{gathered}
$$

We distinguish variables corresponding to prototypes from those corresponding to massproduced goods by an accent in the form of a question mark, ? (firms that can only produce prototypes are still wondering about their ideal production process). Indexing the differentiated varieties of goods by $h$, we denote output of prototype $h$ made with a process of type $j$ in city $i$ by $?_{i}^{j}(h) . Q_{i}^{j}$ is the unit cost for firms producing prototypes using a process of type $j$ in city $i$, and $w_{i}^{j}$ is the wage per unit of labor for the corresponding workers. Note that $Q_{i}^{j}$ decreases as $l_{i}^{j}$ increases: there are localization economies that reduce unit costs when there is a larger supply of labor with the relevant aptitude in the same city (which also implies more firms using the same type of process in the same city). This is because the larger the supply of labor with the same aptitude in a city, the larger the range of intermediate varieties produced in equilibrium; this in turn reduces individual firm costs according to (2).

When a firm finds its ideal production process, it can engage in mass production at a fraction $\rho$ of the cost of producing a prototype, where $0<\rho<1$. Thus the cost function for a firm engaged in mass production is

$$
C_{i}^{j}(h)=\rho Q_{i}^{j} x_{i}^{j}(h),
$$

where $x_{i}^{j}(h)$ denotes the output of massproduced $\operatorname{good} h$, made with a process of type $j$, in city $i$.

With respect to the internal structure of cities, there are congestion costs in each city incurred in labor time and parameterized by $\tau(>0)$. Labor supply, $l_{i}^{j}$, and population, $L_{i}^{j}$, with aptitude $j$ in city $i$ are related by the following expression:

$$
l_{i}^{j}=L_{i}^{j}\left(1-\tau \sum_{j=1}^{m} L_{i}^{j}\right) .
$$

This corresponds to a situation in which workers live spread along linear cities in land plots of unit length, work at the city center, have one unit of labor time, and lose in commuting a fraction of their labor time equal to $2 \tau$ times the distance traveled. The expected wage income of a worker with aptitude $j$ in city $i$ is then $(1-\tau$ $\left.\sum_{j=1}^{m} L_{i}^{j}\right) w_{i}^{j}$, where the higher land rents paid by those living closer to the city center are offset by lower commuting costs (see Fujita [1989] for details and several generalizations).

\section{B. Preferences}

Turning to consumers, we assume that they have a zero rate of time preference. ${ }^{6}$ Each period consumers allocate a fraction $\mu$ of their expenditure to prototypes and a fraction $1-\mu$ to mass-produced goods. We can interpret this

\footnotetext{
${ }^{6}$ Note that there is no form of accumulation in this model. All of consumers' savings are invested in financing firms' start-up costs. In order to provide a nonnegative return on investment, each firms' expected profit stream must be sufficient to recover its start-up cost. This limits the number of new firms, and hence investment, at every period. Given that when calculating a firm's expected profit stream, single-period profits are already discounted by the probability that the firm closes down in any period, $\delta$, introducing an additional discount rate through intertemporal consumer preferences would only obscure expressions without changing the nature of our results.
} 
assumption as there being some fraction of population that prefers to buy the most novel goods, and another fraction that prefers to consume more established products. This separation between the prototype and mass-production markets greatly helps us to obtain closed-form solutions. ${ }^{7}$ The instantaneous indirect utility of a consumer in city $i$ is

$$
V_{i}=\stackrel{?}{P}-\mu P^{-(1-\mu)} e_{i}^{j},
$$

where $e_{i}$ denotes individual expenditure,

$$
\begin{aligned}
& \stackrel{?}{P}=\left\{\sum_{j=1}^{m} \iint\left[\stackrel{?}{p}_{i}^{j}(h)\right]^{1-\sigma} \mathrm{d} h \mathrm{~d} i\right\}^{1 /(1-\sigma)}, \\
& P=\left\{\sum_{j=1}^{m} \iint\left[p_{i}^{j}(h)\right]^{1-\sigma} \mathrm{d} h \mathrm{~d} i\right\}^{1 /(1-\sigma)},
\end{aligned}
$$

are the appropriate price indices of prototypes and mass-produced goods respectively, and $\stackrel{?}{p}_{i}^{j}(h)$ and $p_{i}^{j}(h)$ denote the prices of individual varieties of prototypes and mass-produced goods respectively. Double integration over $h$ and $i$ and summation over $j$ include in the price indices all varieties produced with any type of

\footnotetext{
${ }^{7}$ Nevertheless, if we were instead to make prototypes and mass-produced goods indistinguishable from the point of view of consumers, our results would be substantively unaffected. There would still be a tension between diversity, which reduces the cost of searching for the ideal process, and specialization, which reduces production costs. The only noteworthy difference is that, with no separate market for prototypes, a firm would always switch to mass production as soon as it found its ideal process. Specifically, in terms of our main result in Proposition 1, we would still need to impose conditions analogous to $1,3,4$, and 5 -which under this alternative specification we could no longer write down explicitly. We just would not need a condition analogous to 2 -which reduces to $\rho<1$, and is thus trivially satisfied. At the same time, it is not difficult to think of examples where the segmentation between prototypes and mass-produced goods is quite relevant. For instance, it is common practice for Japanese electronics firms to sell prototypes of their goods to consumers before producing them at mass scale; in doing this they target a specific group of consumers through distinct distribution channels. Similarly, some of Microsoft's customers are willing to purchase a $\beta$-version of its latest operating system for US\$60, whereas others are more than happy to wait until the first service pack is released.
}

process in any city. These price indices are equal in all cities because all final goods, whether prototypes or mass produced, are freely tradable across cities. All prototypes enter consumer preferences with the same elasticity of substitution $\sigma(>2)$, and so do all massproduced goods. ${ }^{8}$

\section{Income and Migration}

National income, $Y$, is the sum of expenditure and investment:

$$
Y=\sum_{j=1}^{m} \int L_{i}^{j} e_{i}^{j} \mathrm{~d} i+\stackrel{?}{P}^{\mu} P^{1-\mu} F \stackrel{\circ}{n} .
$$

$L_{i}^{j}$ denotes population with aptitude $j$ in city $i$. Investment, $\stackrel{?}{P}^{\mu} P^{1-\mu} F \stackrel{\circ}{ }$, comes from the aggregation of the start-up costs incurred by newly created firms (this start-up cost is incurred only once, when the firm is first created). To come up with a new product, but not with the ideal way to produce it, firms must spend $F$ on market research, purchasing the same combination of goods bought by the representative consumer (hence the presence of the price indices in this expression). Finally, $n$ denotes the total number of new firms.

To keep matters simple, we make assumptions about migration to ensure that we have at most the following two kinds of cities.

Definition 1 [Specialized City]: A city is said to be (fully) specialized if all its workers have the same aptitude, so that all local firms use the same type of production process.

Definition 2 [Diversified City]: A city is said to be (fully) diversified if it has the same proportion of workers with each of the $m$ aptitudes, so that there are equal proportions of firms using each of the $m$ types of production process.

To this effect, we assume that workers know the population in each city, but they have im-

\footnotetext{
${ }^{8}$ The restriction $\sigma>2$ is required for a finite equilibrium number of firms. If $\sigma<2$, an increase in the number of firms reduces the start-up cost $\stackrel{?}{P}^{\mu} P^{1-\mu} F$ so much as to make further firm entry ever more profitable.
} 
perfect information about the distribution of each city's workforce across aptitudes. Specifically they only know which, if any, is each city's "dominant" specialization, where a city is said to have a dominant specialization if the largest group of local workers with the same aptitude is above some large enough threshold. Further, workers form their expectations about income in each city as if cities with a dominant specialization were fully specialized, and as if cities with no dominant specialization were fully diversified. With all workers forming their expectations in this way, their expectations turn out to be rational. A city with a dominant specialization attracts only workers with the dominant aptitude, and so in steady state is fully specialized. A city with no dominant specialization seems equally attractive for workers of all aptitudes, and so in steady state is fully diversified. We further assume that each worker can migrate only every once in a while. ${ }^{9}$ This reflects that considerations such as marriage, childbearing, or divorce greatly affect people's ability to migrate at certain periods (Michael J. Greenwood, 1997). It also precludes situations in which all workers can relocate simultaneously where there would be nothing by which to identify a city (so that we remain consistent with cities being stable in their size and sectoral composition). As a result of this migration possibility all workers are equally well off in equilibrium.

\section{City Formation}

Each potential site for a city is controlled by a different land development company or land developer, not all of which will be active in equilibrium. Developers have the ability to tax local land rents and to make transfers to local workers. When active, each land developer commits to a contract with any potential worker in its city that specifies the size of the city, whether it has a dominant sector and if so which, and any transfers. ${ }^{10}$ It designs its con-

\footnotetext{
${ }^{9}$ This includes migrations within each city, so as to avoid issues related to endogenous neighborhood formation which are not the focus of this paper.

${ }^{10}$ See Henderson and Randy Becker (2000) for a discussion of various instruments that allow developers and communities to control a city's size and composition.
}

tract so as to maximize its profit, that is total local land rent net of any transfers, subject to workers' participation constraint. There is free entry and perfect competition amongst land developers. This mechanism for city creation is supported by the overwhelming evidence regarding the role of "large" private agents in city formation in the United States (Joel Garreau, 1991; Henderson and Arindam Mitra, 1996; Henderson and Jacques-François Thisse, 2001). At the same time, even in the absence of land developers, municipal governments with taxraising powers can play an equivalent role. ${ }^{11}$ Our main results can be derived both with and without land developers-we discuss in Section IV the few changes resulting from eliminating them.

\section{E. Equilibrium Definition}

Finally, a steady-state equilibrium in this model is a configuration such that all of the following are true. Each developer offers a contract designed so as to maximize its profits. Each consumer/worker allocates her income between consumption and savings, allocates her expenditure across goods, and takes her migration decisions so as to maximize expected utility. Each firm chooses a location/production strategy and prices so as to maximize its expected lifetime profits. All profit opportunities are exploited, and the urban structure is constant over time (where by urban structure we mean the number of new firms, $\stackrel{n}{n}$, the numbers of prototype producers, $\stackrel{n}{i}_{i}^{j}$, the numbers of mass producers, $n_{i}^{j}$, and populations, $L_{i}^{j}$ ).

\section{Equilibrium City Sizes}

We start by deriving a number of static results that will form the basis for the next section, which deals with the intertemporal dimension of our model. We first derive equilibrium output per worker and use this to obtain optimal city sizes. We then show that the activities of perfectly competitive land developers

\footnotetext{
${ }^{11}$ See Fujita (1989) and Becker and Henderson (2000) for a discussion of this issue and for an equivalence result between these two types of institutions.
} 
pin down equilibrium city sizes to the optimal level.

$$
p_{i}^{j}=\rho \frac{\sigma}{\sigma-1} Q_{i}^{j} .
$$

LEMMA 1 [Output per Worker]: In equilibrium, output per worker by firms using processes of type $j$ in city $i$ in a given period is

$$
\frac{?_{n_{i}^{j}}^{?} x_{i}^{j}+\rho n_{i}^{j} x_{i}^{j}}{L_{i}^{j}}=\left(L_{i}^{j}\right)^{\varepsilon}\left(1-\tau \sum_{j=1}^{m} L_{i}^{j}\right)^{\varepsilon+1} .
$$

\section{PROOF:}

Total demand for each variety is the sum of consumer demand, obtained by application of Roy's identity to (5) and integration over all consumers, and demand by newly created firms, obtained by application of Shephard's Lemma to their one-off start-up cost, $P^{\mu} P^{1-\mu} F$, and multiplication by the number of new firms. The product market-clearing conditions for, respectively, prototypes and mass-produced goods made with a process of type $j$ in city $i$ are

$$
\begin{gathered}
\stackrel{?}{x_{i}^{j}}=\mu\left(\stackrel{?}{p_{i}^{j}}\right)^{-\sigma} \stackrel{?}{P}^{\sigma-1} Y, \\
x_{i}^{j}=(1-\mu)\left(p_{i}^{j}\right)^{-\sigma} P^{\sigma-1} Y .
\end{gathered}
$$

Note that we have dropped index $h$, since shortrun equilibrium values may vary by city and type of process/aptitude, but do not vary by variety. Using (1) and (3), single-period operational profits can be written as

$$
\begin{gathered}
{\stackrel{?}{\pi_{i}^{j}}}^{j}=\left(\stackrel{?}{p_{i}^{j}}-Q_{i}^{j}\right) \stackrel{?}{x_{i}^{j}}, \\
\pi_{i}^{j}=\left(p_{i}^{j}-\rho Q_{i}^{j}\right) x_{i}^{j} .
\end{gathered}
$$

Maximizing (11) and (12) with respect to prices, and using (9) and (10), gives the profitmaximizing prices for each prototype and for each mass-produced good firm. They are fixed relative markups over marginal costs:

$$
\stackrel{?}{p}_{i}^{j}=\frac{\sigma}{\sigma-1} Q_{i}^{j},
$$

Substituting (9), (10), (13), and (14) into (11) and (12) yields maximized operational profits for prototype and mass-produced good firms:

$$
\stackrel{?}{\pi}_{i}^{j}=\mu \frac{1}{\sigma}\left[\frac{\sigma-1}{\sigma} \frac{\stackrel{?}{P}}{Q_{i}^{j}}\right]^{\sigma-1} Y,
$$

$$
\pi_{i}^{j}=(1-\mu) \frac{1}{\sigma}\left[\frac{1}{\rho} \frac{\sigma-1}{\sigma} \frac{P}{Q_{i}^{j}}\right]^{\sigma-1} Y .
$$

Demand for labor can be obtained by application of Shephard's Lemma to (1)-(3) and integration over varieties. The labor marketclearing condition for workers with aptitude $j$ in city $i$ is then

$$
\begin{aligned}
l_{i}^{j} & =\stackrel{?}{n}_{i}^{j} \frac{\partial \stackrel{?}{C}_{i}^{j}}{\partial w_{i}^{j}}+n_{i}^{j} \frac{\partial C_{i}^{j}}{\partial w_{i}^{j}} \\
& =\left(l_{i}^{j}\right)^{-\varepsilon}\left(\stackrel{?}{n}_{i}^{j} x_{i}^{j}+\rho n_{i}^{j} x_{i}^{j}\right) .
\end{aligned}
$$

Substituting (4) into (17), rearranging, and dividing by $L_{i}^{j}$ yields the result.

We can now use this expression for equilibrium output per worker to derive optimal city size.

LEMMA 2 [Optimal City Size]: Optimal city size is

$$
L^{*} \equiv \frac{\varepsilon}{(2 \varepsilon+1) \tau} .
$$

\section{PROOF:}

For any given shares of local population with each aptitude, output per worker in each city, as derived in Lemma 1, and hence the utility of residents, are maximized for $L_{i}=L^{*}$.

The size of a city affects its efficiency by changing the balance between the economies of 
localization and congestion costs. Optimal city size increases with localization economies, as measured by $\varepsilon$, and diminishes with the congestion costs parameter, $\tau$. Note that optimal size for any city is independent of the composition of its population, and is thus the same for diversified and for specialized cities. ${ }^{12}$ Note further that this optimal size is finite. With free entry by competitive profit-maximizing developers into a large urban system, if a finite optimal city size exists, the Henry George Theorem applies.

LEMMA 3 [The Henry George Theorem]: In equilibrium, all cities achieve optimal size, and developers transfer all land rents in their city to local workers, filling the gap between the private and the public marginal product of labor.

This is a classic result in urban economics (Jan Serck-Hanssen, 1969; David A. Starrett, 1974; William S. Vickrey, 1977). ${ }^{13}$ The intuition behind it is straightforward (see Becker and Henderson [2000] for a particularly helpful derivation, and Chapter 4 in Fujita and Thisse [2002] for a detailed discussion). Free entry forces competitive profit-maximizing developers to operate at optimal city size. To attain this size they must make transfers that cover the gap opened by localization economies between workers' social and private marginal products. With zero profits for developers, total land rents equal total transfers, and thus are just enough to cover that gap.

Before moving on to explore the intertemporal dimension of our framework, it is useful to consider a static benchmark with no learning stage for firms. In terms of the model, this

\footnotetext{
${ }^{12}$ In our model, a larger city size in itself is not helpful, but a larger population with a given aptitude is. This is because aggregate production with any one type of process is a homogenous of degree $\varepsilon+1$ function of net local labor of the corresponding aptitude, as can be seen in (17). It might be more realistic (but less tractable) to have the intensity of aggregate increasing returns decreasing with net local employment above a given threshold for each type of process. This would yield a larger optimal size for diversified cities than for specialized cities.

${ }^{13}$ The best-known version of the Henry George Theorem is associated with local public goods (Frank Flatters et al., 1974; Joseph E. Stiglitz, 1977; Richard J. Arnott and Stiglitz, 1979).
}

would require that upon entry every firm knew its ideal process and that there was no market for prototypes. In this case $\vec{n}_{i}^{j}=0$, and output per worker, as given in Lemma 1, as well as developers' profits, will be maximized when all cities are fully specialized (as in Henderson [1974] and most subsequent models of systems of cities). In that static framework, diversity only imposes costs, since adding labor with a different aptitude increases congestion without fostering localization economies. Learning changes this, by creating dynamic advantages to diversity: diversity allows learning firms to produce a sequence of prototypes with different processes without costly relocations. This is a crucial innovation of this model. It fundamentally affects the equilibrium urban system by providing a motivation for the coexistence of diversified and specialized cities and for the location of production to change over the life cycle.

\section{Nursery Cities}

Whenever diversified and specialized cities coexist, diversified cities act as a nursery for firms by facilitating experimentation. Specialized cities, on the other hand, provide an environment where firms can take full advantage of lower production costs due to localization economies. We now consider a configuration where firms relocate across these two environments when they find their ideal process. In checking whether this is a steady state, we make sure that it is in firms' best interest not to relocate at a different point in time.

Definition 3 [Nursery Configuration]: The nursery configuration is characterized as follows. Diversified and specialized cities coexist. The same proportion of cities specializes in each type of process. Each new firm locates in a diversified city and produces prototypes using a different type of production process each period. As soon as a firm finds its ideal production process, and only then, it relocates to a city specialized in that particular type of process and commences mass production.

The necessary and sufficient conditions for the nursery configuration to be a steady state turn out to depend on three elements: the 
relative production costs in diversified and specialized cities, the relative number of prototype to mass producers, and the expected duration of the prototype and mass-production stages. The following three lemmas characterize these components.

\section{A. Relative Costs, Relative Number of Firms, and Expected Production Periods}

To simplify notation, let us replace subindex $i$ with $D$ for diversified city variables and with $S$ for specialized city variables. Further, denote by $N_{D}$ the equilibrium number of diversified cities, and by $N_{S}$ the equilibrium number of cities specialized in each of the $m$ types of production processes.

LEMMA 4 [Relative Costs]: Unit production costs in diversified cities relative to those in specialized cities are

$$
\frac{Q_{D}}{Q_{S}}=m^{\varepsilon}
$$

PROOF:

The unit production costs of (2) become

$$
\begin{aligned}
Q_{D} & =\left[\frac{L^{*}}{m}\left(1-\tau L^{*}\right)\right]^{-\varepsilon} w_{D}, \\
Q_{S} & =\left[L^{*}\left(1-\tau L^{*}\right)\right]^{-\varepsilon} w_{S},
\end{aligned}
$$

when valued in diversified cities and in specialized cities respectively. Since, by Lemma 2, all cities are of size $L^{*}$ and thus workers receive the same transfers everywhere, migration ensures that in steady state, wages are equalized across cities: $w_{D}=w_{S}$. Taking the ratio of the two equations in (18) then yields the result.

By strengthening localization economies, an increase in the size of each sector present in each city has a cost-reducing effect. But it also has a cost-increasing effect by increasing city size, worsening congestion, and raising labor costs. In specialized cities, all firms use the same type of production process and contribute to both effects. In diversified cities, however, only firms using the same type of process in any one period (a fraction $1 / \mathrm{m}$ of the total) contribute to localization economies, while all firms impose on each other congestion costs. ${ }^{14}$ Thus, a diversified city is a more costly place to produce than a specialized city by a factor $m^{\varepsilon}$.

LEMMA 5 [Relative Number of Firms]: The ratio of the total number of prototype producers to the total number of mass producers in the nursery configuration is

$$
\begin{aligned}
\Omega & \equiv \frac{N_{D} \stackrel{?}{n}_{D}}{N_{S} n_{S}} \\
& =\frac{\delta(m+1)-1+(1-\delta)^{m-1}(1-2 \delta)}{(1-\delta)^{2}\left[1-(1-\delta)^{m-2}(1-2 \delta)\right]} .
\end{aligned}
$$

\section{PROOF:}

The probability that a firm following the nursery strategy finds its ideal process in period $t$, for $1 \leq t \leq m-2$, is equal to the probability of such a firm not having closed down, $(1-\delta)^{t}$, times the probability that the process it tries in this period is its ideal one, $1 / \mathrm{m}$. If a firm following the nursery strategy gets to produce $m-1$ prototypes and remains in operation [which happens with probability $(2 / \mathrm{m})$ $\left.(1-\delta)^{m-1}\right]$, it leaves the diversified city at that point since it has either just found its ideal process or otherwise knows that the only process left to try must be its ideal one. The total number of firms relocating from diversified to specialized cities each period is therefore a fraction $\left[\sum_{t=1}^{m-2}(1 / m)(1-\delta)^{t}+(2 / m)(1-\right.$ $\delta)^{m-1}$ ] of the number of firms starting up each period, $\stackrel{n}{ }$. After simplification, this becomes $\frac{1-\delta}{\delta m}\left[1-(1-\delta)^{m-2}(1-2 \delta)\right] n$. The number of firms arriving each period in specialized cities is a fraction $(1-\delta)$ of those that relocated from diversified cities the previous period, since a fraction $\delta$ closes down in the period of idleness that makes relocation costly. With a constant number of firms in each city, this quantity must also equal the number of firms closing down in specialized cities each period, $\delta m N_{S} n_{S}$ :

\footnotetext{
${ }^{14}$ For the sake of symmetry, in steady state there must be the same proportion of firms using each type of process in each diversified city in any period. Let us suppose that each firm chooses the order in which to try different processes randomly. Since there is a continuum of firms, by the law of large numbers, symmetry will be attained.
} 


$$
\begin{aligned}
& \frac{(1-\delta)^{2}}{\delta m}\left[1-(1-\delta)^{m-2}(1-2 \delta)\right] \stackrel{\circ}{ } \\
& \quad=\delta m N_{S} n_{S}
\end{aligned}
$$

In steady state, the number of firms created each period must equal the total number of closures, which is a fraction $\delta$ of all existing firms:

(20) $\stackrel{\circ}{n}=\delta\left(N_{D} m n_{D}+\frac{\delta}{1-\delta} m N_{S} n_{S}+m N_{S} n_{S}\right)$.

Eliminating $n$ from (19) and (20) yields the result.

$\Omega$ can be seen as a measure of how unlikely a firm is to find its ideal production process. Since firms can engage in mass production only once they learn about their ideal process, whenever firms are unlikely to find their ideal process, the number of prototype producers is large relative to the number of mass producers. $\Omega$ is a function of only two parameters, the number of types of production process, $m$, and the probability of a firm closing down in any period, $\delta$. The larger either of these two parameters, the less likely that a firm will see itself through to the mass-production stage $\left(\frac{\partial \Omega}{\partial m}>0, \frac{\partial \Omega}{\partial \delta}>0\right)$. Intuitively, if there are many possibilities for a firm's ideal production process or if the closure rate is high, there is a large chance that a firm will close down before it can find its ideal process.

LEMMA 6 [Expected Production Periods]: The number of periods that a firm following the nursery configuration strategy expects to spend producing prototypes in a diversified city is

$$
\stackrel{\dot{\Delta}}{=}=\frac{\delta(m+1)-1+(1-\delta)^{m-1}(1-2 \delta)}{m \delta^{2}} .
$$

The number of periods it expects to engage in mass production in a city where all workers have the aptitude that corresponds to its ideal process is

$$
\Delta=\frac{(1-\delta)^{2}-(1-\delta)^{m}(1-2 \delta)}{m \delta^{2}} .
$$

Now consider a firm that instead locates first in a specialized city, relocates across specialized cities to try different production processes, and on find- ing its ideal process fixes its location. The number of periods that this firm expects to spend producing prototypes in different specialized cities is

$$
\begin{aligned}
& {\stackrel{\vartheta}{\dot{\Delta}_{O S C}}}=\frac{1}{m(2-\delta)^{2} \delta^{2}}\{(1+m)(2-\delta) \delta-1 \\
& \left.+(1-\delta)^{2(m-1)}[1-2(2-\delta) \delta]\right\} .
\end{aligned}
$$

The number of periods it expects to engage in mass production in a city where all workers have the aptitude that corresponds to its ideal process is

$$
\begin{aligned}
\Delta_{O S C}= & \frac{1}{m(2-\delta) \delta^{2}}\{1-\delta \\
& \left.\quad+(1-\delta)^{2(m-1)}[(3-\delta) \delta-1]\right\} .
\end{aligned}
$$

PROOF:

Since the expected duration of a firm is $1 / \delta$, and since in the nursery configuration, firms that find their ideal process have a probability $(1-\delta)$ of closing while relocating to a city of the relevant specialization, we have

$$
\stackrel{?}{\Delta}+\frac{\Delta}{1-\delta}=\frac{1}{\delta} .
$$

Also,

$$
\begin{aligned}
\dot{\Delta}= & \sum_{t=1}^{m-2} t\left[\frac{1}{m}(1-\delta)^{t-1}\right. \\
& \left.+\frac{m-t}{m} \delta(1-\delta)^{t-1}\right] \\
& +(m-1) \frac{2}{m}(1-\delta)^{m-2},
\end{aligned}
$$

$$
\begin{aligned}
\dot{\Delta}_{O S C}= & \sum_{t=1}^{m-2} t\left[\frac{1}{m}(1-\delta)^{2(t-1)}\right. \\
& \left.+\frac{m-t}{m}(1-\delta)^{2(t-1)} \delta(2-\delta)\right] \\
& +(m-1) \frac{2}{m}(1-\delta)^{2(m-2)},
\end{aligned}
$$




$$
\begin{aligned}
\Delta_{O S C}= & \left(\sum_{t=1}^{m-2} \frac{1}{m}(1-\delta)^{2 t-1}\right. \\
& \left.+\frac{1}{m}(1-\delta)^{2(m-1)}\right) \frac{1}{\delta} .
\end{aligned}
$$

Expansion and simplification of (22)-(24), together with (21), yields the expressions in the lemma.

To close the model we need to solve for the general-equilibrium level of investment, which yields the number of new firms created each period. It is particularly convenient to use James Tobin's (1969) $q$ approach. Tobin's $q$ is the ratio of the value of one unit of capital to its replacement cost. In steady state, the general-equilibrium level of investment is that for which $q=1$. The asset value of a new firm is equal to its expected stream of operational profits. The cost of its replacement is the start-up cost. In this context, Tobin's $q=1$ condition is therefore equivalent to a condition of zero expected net profits for firms: ${ }^{15}$

$$
q=\frac{\stackrel{?}{\Delta} \stackrel{?}{\pi}_{D}+\Delta \pi_{S}}{\stackrel{?}{P}^{\mu} P^{1-\mu} F}=1 .
$$

We now have everything we need to derive necessary and sufficient conditions for the nursery configuration to be a steady state.

\section{B. Necessary and Sufficient Conditions for Nursery Cities}

PROPOSITION 1 [Nursery Steady State]: The nursery configuration is a steady state if and only if the following five conditions are satisfied.

Condition 1: Firms relocate to a specialized city once they find their ideal process:

\footnotetext{
15 This property has been used in applications of Tobin's $q$ approach to endogenous growth models with monopolistic competition (Richard E. Baldwin and Rikard Forslid, 2000).
}

$$
m^{\varepsilon(\sigma-1)} \geq \frac{1}{1-\delta}
$$

Condition 2: Firms switch to mass production once they find their ideal process:

$$
m^{\varepsilon(\sigma-1)} \leq \frac{1-\mu}{\mu} \Omega .
$$

Condition 3: Firms stay in diversified cities until they find their ideal process:

$$
m^{\varepsilon(\sigma-1)} \leq \frac{1}{1-\delta}+\frac{1-\delta}{2} \frac{1-\mu}{\mu} \Omega .
$$

Condition 4: Firms do not give up the search for their ideal process:

$$
\begin{aligned}
m^{\varepsilon(\sigma-1)} \leq & \frac{m \delta}{m-1+\delta} \\
& \times\left[\stackrel{?}{\Delta}+\left(\Delta-\frac{1-\delta}{m \delta}\right) \frac{1-\mu}{\mu} \Omega\right] .
\end{aligned}
$$

Condition 5: Firms do not search for their ideal process by relocating across specialized cities:

$$
m^{\varepsilon(\sigma-1)} \leq \frac{\stackrel{?}{\Delta}}{\dot{\vec{\Delta}}_{O S C}}+\frac{\Delta-\Delta_{O S C}}{\dot{\vec{\Delta}}_{O S C}} \frac{1-\mu}{\mu} \Omega .
$$

PROOF:

To ensure that the nursery configuration is a steady state, we need to check the unprofitability of all possible deviations. This requires calculating several profitability ratios. From (15), (16), and Lemma 4,

$$
\frac{?^{\pi_{S}}}{\pi_{D}}=\frac{\pi_{S}}{\pi_{D}}=\left(\frac{Q_{D}}{Q_{S}}\right)^{\sigma-1}=m^{\varepsilon(\sigma-1)}
$$

In the nursery configuration, there are $m \hat{n}_{D}$ prototype producers and no mass producers in each of the $N_{D}$ diversified cities, and there are $n_{S}$ mass producers and no prototype producers in each of the $m N_{S}$ specialized cities. Hence, using (13) and (14), the price indices of (6) and (7) become 


$$
\begin{aligned}
& \stackrel{?}{P}=\frac{\sigma}{\sigma-1}\left(N_{D} m \stackrel{?}{n_{D}}\right)^{1 /(1-\sigma)} Q_{D}, \\
& P=\rho \frac{\sigma}{\sigma-1}\left(m N_{S} n_{S}\right)^{1 /(1-\sigma)} Q_{S} .
\end{aligned}
$$

$$
\frac{{\stackrel{?}{\pi_{S}}}}{\pi_{S}}=\frac{?^{\pi_{D}}}{\pi_{D}} \leq 1 .
$$

Using (26) and (31), (33) becomes Condition 2. Conditions 1 and 2 jointly guarantee that any firm in a diversified city that knows its ideal process wants to relocate to a city of the relevant specialization and engage in mass production there.

The next issue is whether a firm located in a diversified city stays there until it finds its ideal process. Alternatively, it could relocate from a diversified to a specialized city after making $m-2$ prototypes without finding its ideal process, not yet knowing which of the two remaining processes is its ideal one. This is not profitable if and only if

$$
\begin{gathered}
(1-\delta) \stackrel{?}{\pi}_{S}+\frac{1}{2} \frac{(1-\delta)^{3}}{\delta} \pi_{S} \\
\leq \stackrel{?}{\pi}_{D}+\frac{1}{2} \frac{(1-\delta)^{2}}{\delta} \pi_{S} .
\end{gathered}
$$

Taking the ratio of (30) and (29), and using the definition of $\Omega$, yields

$$
\frac{\pi_{S}}{\pi_{D}}=\frac{1-\mu}{\mu} \Omega .
$$

Let us start ruling out possible deviations from the end of a firm's life cycle. Consider a firm in a diversified city that knows its ideal process. It can follow the nursery strategy, relocate to a city of the relevant specialization and, if it survives the relocation period (which happens with probability $1-\delta$ ), engage in mass production there for an expected $1 / \delta$ period. Alternatively, it could engage in mass production in the diversified city. The latter option is not a profitable deviation if and only if

$$
\frac{\pi_{D}}{\delta} \leq(1-\delta) \frac{\pi_{S}}{\delta}
$$

Substituting (26) into (32) and rearranging yields Condition 1. Another possible deviation for a firm that knows its ideal process is to nevertheless keep producing prototypes. But this is not more profitable than engaging in mass production in the same type of city, provided that
Substituting (26) and (31) into (34) and rearranging yields Condition 3 .

There are other possible deviations from the nursery strategy for a firm that initially locates in a diversified city. A firm could relocate from a diversified to a specialized city, not just with two processes left to try, but with any number of untried processes between 2 and $m-1$. If it did so and its ideal process did not correspond to this city's specialization, it could keep trying to find its ideal process by relocating to other specialized cities. At some point it could give up the search for its ideal process and remain in a specialized city producing prototypes, or it could eventually return to a diversified city. Appendix B shows that all of these deviations can be ruled out without imposing any additional parameter constraints on the nursery steady state beyond those of Conditions 1-5.

The final step is to show that a firm does not find it profitable to locate initially in a specialized rather than in a diversified city. Appendix $B$ rules out deviations involving relocation from a specialized to a diversified city, or a firm giving up the search for its ideal process after producing more than one prototype. Given this, 
there are only two other possible deviations from the nursery strategy.

A firm could locate initially in a specialized city and remain there regardless of the outcome of the first trial. If it manages to survive the first period in a specialized city (which happens with probability $1-\delta$ ), it will be able to engage in mass production with probability $1 / m$ or else will keep producing prototypes. This is not a profitable deviation from the nursery strategy if and only if

$$
\begin{aligned}
{\stackrel{?}{\pi_{S}}} & +(1-\delta)\left[\frac{1}{m} \frac{\pi_{S}}{\delta}+\frac{m-1}{m} \frac{?}{\pi_{S}}\right] \\
& \leq \stackrel{\dot{\Delta}}{\delta}{\stackrel{?}{\pi_{D}}}+\Delta \pi_{S} .
\end{aligned}
$$

Substituting (26) and (31) into (35) and rearranging yields Condition 4 .

The remaining alternative is for a firm to locate initially in a specialized city and to search for its ideal process solely in specialized cities, which would mean relocating from one specialized city to another between prototypes in order to try different production processes until finding the ideal one, and then staying in a city of the relevant specialization to engage in mass production. This is not a profitable deviation from the nursery strategy if and only if

$$
\stackrel{?}{\Delta}_{O S C}{\stackrel{?}{\pi_{S}}}+\Delta_{O S C} \pi_{S} \leq \stackrel{?}{\Delta} \stackrel{?}{D}_{D}+\Delta \pi_{S} .
$$

Substituting (26) and (31) into (36) and rearranging yields Condition 5 .

Therefore, if Conditions 1-5 are satisfied, with all firms following the nursery strategy, no firm finds it profitable to deviate from this strategy.

\section{Discussion}

Condition 1 says that for a firm to want to relocate when it finds its ideal process, unit production costs need to be sufficiently lower in specialized cities so as to make the relocation cost $(\delta)$ worth incurring.

Condition 2 ensures that firms switch to mass production as soon as they can. For it to be satisfied, mass production needs to be sufficiently attractive. The attractiveness of mass production relative to prototype production depends on relative costs, relative market sizes $[(1-\mu) / \mu]$, and the relative number of competitors in each market $\left(\Omega=N_{D} m ?_{D} / N_{S} m n_{S}\right)$.

Condition 3 considers relocation from a diversified to a specialized city by a firm that has failed to find its ideal process and still has another two possibilities to try. This firm relocates one period earlier than under the nursery strategy, and so has a lower probability, $1-\delta$, of making its next prototype. On the other hand, if it makes this next prototype, it will do so at a lower cost. However, it may turn out (with probability $1 / 2$ ) that its ideal process is not this next one but the one it left to try last. Then it has to relocate once more than under the nursery strategy, delaying the mass-production stage. Condition 3 is satisfied when mass production is comparatively attractive, when the cost advantage of specialized cities is not too large, and when (if Condition 4 is satisfied) relocation costs (as measured by $\delta$ ) are not too low.

According to Condition 4, a firm is deterred from giving up the search for its ideal process when mass production is comparatively attractive. It is also more likely to stick to the nursery strategy when the additional costs associated with diversified cities are not too large, and when the expected number of periods producing

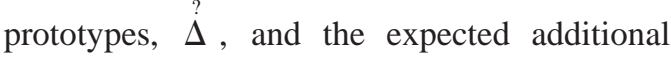
periods engaged in mass production under the nursery strategy, $\Delta-(1-\delta) / m \delta$, are large relative to the expected number of periods producing prototypes if it only tries one process, $(m-1+\delta) / m \delta$.

Finally, a firm may consider searching for its ideal process by relocating from one specialized city to another. Condition 5 says that it must then take into account a lower probability of finding its ideal process and, conditional on survival, a longer expected time before it discovers it. Consequently, this deviation is deterred by a low cost advantage of specialized cities, and by mass production being relatively attractive.

On the whole, the nursery strategy can be seen as a risky investment. Whether it is worthwhile or not depends on its cost, on the payoff if successful, and on the likelihood of success. The nursery strategy is costly because, in a diversified city, all firms impose congestion costs on each other, but only those using the 
same type of process create cost-reducing localization economies, and this results in comparatively higher production costs. If the cost advantage of specialized cities is too large, a firm may find it worthwhile to produce in specialized cities before finding its ideal process (Conditions 3-5). On the other hand, if the cost advantage is too small, a firm may never want to incur the cost of moving away from a diversified city (Condition 1). The payoff to learning is also important, and this increases with the size of the market for massproduced goods relative to the market for prototypes $[(1-\mu) / \mu]$. It also depends on how crowded each market is, as measured by the relative number of firms $(\Omega$, which in turn depends on $m$ and $\delta$ ). Finally, the likelihood of a firm finding its ideal process depends on the number of alternatives $(m)$, and the chances of closure in any period $(\delta)$. Figure 1 illustrates the dependence of Conditions $1-5$ on $m$ and $\delta .{ }^{16}$ The area where the nursery configuration is a steady state is shaded in gray.

A larger value of $m$ makes finding the ideal production process more difficult for firms. Consequently, the nursery strategy becomes more attractive than other strategies that involve relocations while producing prototypes. $^{17}$

Regarding $\delta$, a low value of this parameter makes searching for the ideal process across specialized cities a less costly alternative to the nursery strategy (Condition 3 and downward-sloping portion of Condition 5). It also implies that, with all firms following the nursery strategy, a higher proportion of them will get to the mass-production stage.

\footnotetext{
${ }^{16}$ For visual clarity, we ignore that $m$ is an integer. Conditions 1-5 depend only on three parameters other than $m$ and $\delta: \mu, \varepsilon$, and $\sigma$. Figure 1 is plotted for $\mu=0.2$ (prototypes represent 20 percent of the market, with massproduced goods accounting for the remaining 80 percent), $\varepsilon=0.07$ (a 1-percent increase in the amount of labor with a certain aptitude net of commuting costs increases a city's output from that labor by 1.07 percent), and $\sigma=4$ (firms mark up marginal costs by $1 / 3$ ).

17 There are also circumstances (in particular, a very large share of demand being allocated to prototypes) under which the increased uncertainty associated with a larger value of $m$ can deter a firm from trying to find its ideal process (a violation of Condition 4).
}

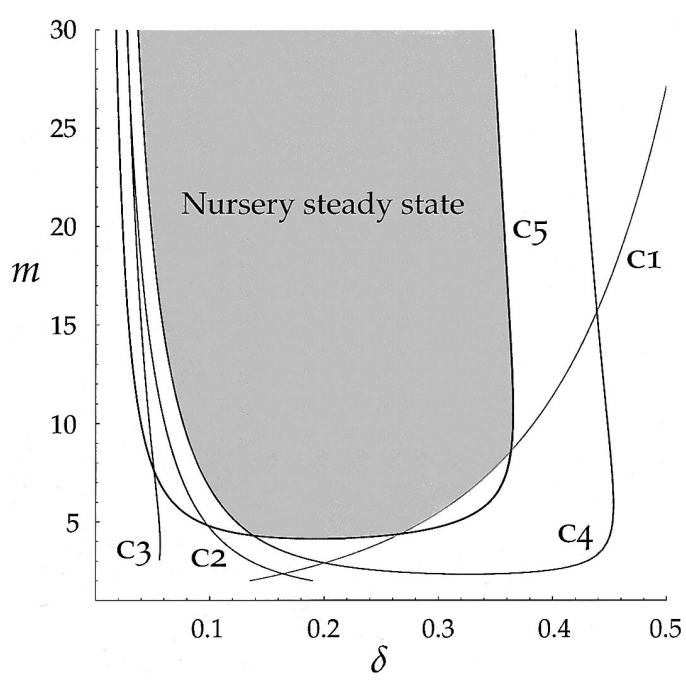

Figure 1. Dependence of Conditions $1-5$ ON $m$ AND $\delta$

This makes it more attractive for a firm to deviate and stop looking for its ideal process (downward-sloping portion of Condition 4), or to keep on producing prototypes even if it finds its ideal process (Condition 2). On the other hand, a high value of $\delta$ makes it unlikely that a firm makes it to the mass-production stage. This increases the importance of getting higher operational profits while producing prototypes, encouraging firms to search for their ideal process across specialized cities (upward-sloping portion of Condition 5) or discouraging them from searching altogether (upward-sloping portion of Condition 4 ). It is therefore for intermediate values of $\delta$ that the nursery configuration is a steady state.

\section{Stability and Uniqueness}

Having derived necessary and sufficient conditions for the nursery configuration to be a steady state, we now show that it has a number of desirable properties. In particular, those same conditions guarantee the stability and uniqueness of this steady state.

Regarding stability, while mobility ensures that workers in all cities are equally well off, there might be configurations where this equality can be broken by a small perturbation in the spatial distribution of workers. Equilibrium sta- 
bility with respect to such perturbations is closely related to optimal city size.

PROPOSITION 2 [Stability]: The steady state is stable with respect to small perturbations in the spatial distribution of workers.

\section{PROOF:}

From Lemmas 1 and 2, local output per worker, and hence the utility of residents, are a concave function of city size, which reaches a global maximum for $L=L^{*}$. Thus, utility equalization across cities for workers with the same aptitude implies that cities of the same type (diversified cities, or cities with the same specialization) can be, at most, of two different sizes: one no greater than the optimal size, $L^{*}$, and another one no smaller than this. Taking the derivative of output per worker, as derived in Lemma 1, with respect to the number of workers of each type in each city, shows that in a city smaller than optimal size, a small positive perturbation makes the city more attractive to workers [and by (18), also to firms] relative to other cities with a similar composition. As workers and firms move in, the size of this city increases. A small negative perturbation has the opposite effect of pushing more and more workers and firms away from such a city. By contrast, in a city no smaller than the optimal size, a small positive perturbation makes the city less attractive, while a small negative perturbation makes the city more attractive to workers and firms. Consequently, stability requires that all cities of the same type are of the same size, and that no city is smaller than $L^{*}$. Lemma 3 ensures that these two conditions are satisfied.

PROPOSITION 3 [Uniqueness]: Whenever the nursery configuration is a steady state, it is the unique steady state.

\section{PROOF:}

Suppose that the nursery configuration is a steady state - Conditions 1-5 are satisfied — and consider any candidate for a second steady state where at least some fraction of firms does not follow the nursery strategy. Let us use $a^{\prime}$ to distinguish variables under this candidate steady state from those that apply when all firms follow the nursery strategy. Denote by $\lambda$ and $1-\lambda$ the fractions of prototype producers located in diversified and specialized cities respectively. Condition 1 ensures that every mass producer fixes its location in a specialized city regardless of the strategies of other firms. Recall that the nursery strategy involves no relocations while a firm searches for its ideal process. A firm could also avoid relocating while searching for its ideal process by fixing its location in a specialized city from the beginning. However, Condition 4 ensures that in this case a firm expects to engage in mass production for fewer periods than if it follows the nursery strategy regardless of what other firms do. Thus, given that the total expected duration of firms is a constant $1 / \delta$, subject to mass production taking place in specialized cities as guaranteed by Condition 1, the fraction of a firm's total duration devoted to mass production is maximized by following the nursery strategy. Consequently, with Conditions 1 and 4 satisfied, any steady state where at least some fraction of firms does not follow the nursery strategy must be characterized by a higher ratio of prototype to mass producers than the nursery steady state: $\Omega^{\prime}>$ $\Omega$. In this candidate for a second steady state, just like in the nursery steady state, by (15), (16), and Lemma 4,

$$
\frac{\stackrel{?}{\pi_{S}^{\prime}}}{\frac{?}{\pi_{D}^{\prime}}}=\frac{\pi_{S}^{\prime}}{\pi_{D}^{\prime}}=m^{\varepsilon(\sigma-1)} .
$$

However, from (6), (7), and (13)-(16),

$$
\frac{\pi_{S}^{\prime}}{\frac{?}{\pi_{D}^{\prime}}}=\frac{1-\mu}{\mu} \Omega^{\prime}\left[\lambda+(1-\lambda) m^{\varepsilon(\sigma-1)}\right] .
$$

By following step by step the proof of Proposition 1, we can derive a set of five conditions for the nursery strategy to provide the highest expected profits for any individual firm under this candidate for a second steady state, and thus for the nursery strategy to be a profitable deviation for any firm not already following it. These conditions are entirely analogous to Conditions $1-5$ but with $\Omega$ replaced by $\Omega^{\prime}[\lambda+$ $\left.(1-\lambda) m^{\varepsilon(\sigma-1)}\right]$, since the only difference is that the profitability ratio in equation (38) re- 
places the one in (31). Given that $\Omega^{\prime}>\Omega$ and that $\left[\lambda+(1-\lambda) m^{\varepsilon(\sigma-1)}\right]>1$, if Conditions $1-5$ are satisfied, it is optimal for every firm to follow the nursery strategy regardless of what other firms do. Hence, the nursery configuration is the unique steady state.

The expected time it takes to find the ideal process is minimized by sticking to a diversified city while trying different processes. Condition 1 ensures that mass production always takes place in specialized cities because production costs are sufficiently lower. Thus, in steady state, if at least some fraction of firms is not following the nursery strategy, there will be relatively fewer firms engaged in mass production, and getting to be one of them will be even more attractive. Hence, if the nursery strategy is optimal when all other firms are following it as well (as guaranteed by Conditions 1-5), then this strategy makes even more sense when some fraction of firms is not following it. Consequently the nursery strategy is a profitable deviation from any other configuration. This results in uniqueness.

While our main results can be rederived without competitive developers, the uniqueness result of Proposition 3 does rely on their presence. This is because, when Conditions $1-5$ are satisfied, everyone prefers to have both diversified and specialized cities. However, in the absence of land developers, configurations with only diversified or only specialized cities could also be equilibria, simply because there would be no coordinating mechanism to create cities of the other type. ${ }^{18}$ Yet, even in this case, the nursery

\footnotetext{
${ }^{18}$ Similarly, equilibrium city sizes could be above optimal size because of a coordination failure preventing an increase in the number of cities. Note that if Conditions 1-5 are not satisfied in equilibrium, there may be only diversified or only specialized cities even without a coordination failure. The discussion paper version of this paper characterizes these alternative equilibria.
}

configuration would unambiguously provide a higher level of welfare than configurations with only diversified or with only specialized cities (see the discussion paper version of this paper, Duranton and Puga [2000b] for a formal proof). ${ }^{19}$ It would thus be natural to expect the emergence of some mechanism for city creation that would act as a coordinating device. Such a mechanism, like competitive developers, would restore uniqueness.

\section{Concluding Remarks}

In the empirical literature and economic policy discussions about which are the best urban economic structures, the debate has been mostly framed in terms of diversity versus specialization, as if the answer was one or the other. This paper suggests instead that both diversified and specialized urban environments are important in a system of cities. There is a role for each type of local economic environment but at different stages of a product's life cycle. Diversified cities are more suited to the early stages of a product's life cycle, whereas more specialized places are better to conduct mass production of fully developed products. A "balanced" urban system may thus not be one where all cities are equally specialized or equally diversified, but one where both diversified and specialized cities coexist. In such a system, some cities specialize in churning new ideas and new products (which requires a diversified base), whereas other cities specialize in more standardized production (which, in turn, is better carried out in a more specialized environment). For manufacturing and services, unlike for agriculture, "sowing" and "reaping" can take place in different locations.

\footnotetext{
${ }^{19}$ The discussion paper version only introduces competitive developers at the very end, so the interested reader can find there our main results rederived without developers.
} 


\section{Appendix A: Unit Costs as Intermediate Prices}

Here we derive from first principles the reduced-form cost functions presented in the text. Suppose there are $m$ monopolistically competitive intermediate service sectors. Each of these sectors employs workers with one of the $m$ possible aptitudes to produce differentiated varieties. The cost function of a sector $j$ intermediate firm producing variety $g$ in city $i$ is

$$
C S_{i}^{j}(g)=\left[\alpha+\beta y_{i}^{j}(g)\right] w_{i}^{j}
$$

where $y_{i}^{j}(g)$ denotes the firm's output. The expression in parenthesis is the unit labor requirement, which has both a fixed and a variable component. Thus, there are increasing returns to scale in the production of each variety of intermediates.

Each of the $m$ types of production process for final-good firms (whether prototype or mass producers) corresponds to the use as inputs of services from one of the $m$ intermediate sectors. Intermediate services are nontradable across cities. All potential varieties (only some of which will be produced in equilibrium) enter symmetrically into the technology of final-good firms with a constant elasticity of substitution $(\varepsilon+1) / \varepsilon$. The cost function of a final-good firm producing prototype $h$, using a process of type $j$, in city $i$ is

$$
\stackrel{?}{C}_{i}^{j}(h)=Q_{i}^{j} \stackrel{?}{x}_{i}^{j}(h)
$$

and that of a final-good firm mass producing good $h$, which uses a process of type $j$, in city $i$ is

$$
C_{i}^{j}(h)=\rho Q_{i}^{j} x_{i}^{j}(h),
$$

where

$$
Q_{i}^{j}=\left\{\int\left[q_{i}^{j}(g)\right]^{-1 / \varepsilon} \mathrm{d} g\right\}^{-\varepsilon},
$$

$0<\rho<1, \varepsilon>0$, and $q_{i}^{j}(g)$ is the price of variety $g$ of intermediate sector $j$ produced in city $i$.

Demand for each intermediate variety is the sum of demand by prototype producers and demand by mass producers, obtained by application of Shephard's Lemma to (A2) and (A3), respectively, and integration over final-good firms. The market-clearing condition for each intermediate variety is then:

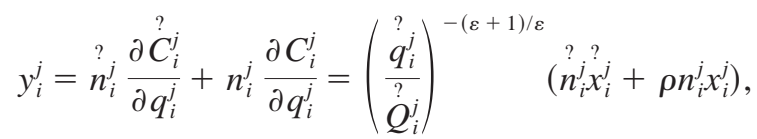

where prices $\grave{q}_{i}^{j}$ still need to be replaced by their profit-maximizing values, and we have dropped index $g$ since all variables take identical values for all intermediate firms in the same sector and city. The profit-maximizing price for each intermediate is a fixed relative markup over marginal cost:

$$
q_{i}^{j}=(\varepsilon+1) \beta w_{i}^{j} .
$$

Free entry and exit in intermediates drives maximized profits to zero. From the zero-profit condition, the only level of output in intermediates consistent with zero profits is 


$$
y_{i}^{j}=\frac{\alpha}{\beta \varepsilon} .
$$

Demand for labor can be obtained by application of Shephard's Lemma to (A1) and integration over varieties. Using (A7), the labor market-clearing condition becomes

$$
l_{i}^{j}=s_{i}^{j} \frac{\partial C S_{i}^{j}}{\partial w_{i}^{j}}=s_{i}^{j}\left[\alpha+\beta y_{i}^{j}\right]=s_{i}^{j} \alpha \frac{\varepsilon+1}{\varepsilon},
$$

where $s_{i}^{j}$ is the equilibrium number of sector $j$ intermediate firms in city $i$.

By choice of units of intermediate output, we can set $\beta=(\varepsilon / \alpha)^{\varepsilon}(\varepsilon+1)^{-(\varepsilon+1)}$. Using (A8) and (A6), the price indices of (A4) simplify into

$$
Q_{i}^{j}=\left[s_{i}^{j}\left(q_{i}^{j}\right)^{-1 / \varepsilon}\right]^{-\varepsilon}=\left(l_{i}^{j}\right)^{-\varepsilon} w_{i}^{j} .
$$

Equations (A2), (A3), and (A9) are the reduced-form cost functions of equations (1)-(3) in the main text.

\section{Appendix B: Further Deviations from the Nursery Strategy}

This Appendix describes further deviations from the nursery strategy besides those directly ruled out by Conditions 1-5, and shows that these do not impose additional parameter constraints on the nursery steady state.

A firm that has been producing prototypes in a diversified city without finding its ideal process could relocate to a specialized city, not just with two processes left to try (which is ruled out by Condition 3), but with any number $t$ of untried processes for $2 \leq t \leq m-1$. If it did so and its ideal process did not correspond to this city's specialization, this firm could keep trying to find its ideal process by relocating to other specialized cities, it could at some point give up the search for its ideal process and remain in a specialized city producing prototypes, or it could eventually return to a diversified city. Denote by $\stackrel{?}{\Delta}(t)$ the expected remaining periods of prototype production for this prototype producer with $t$ untried processes if it continues to follow the nursery strategy, which

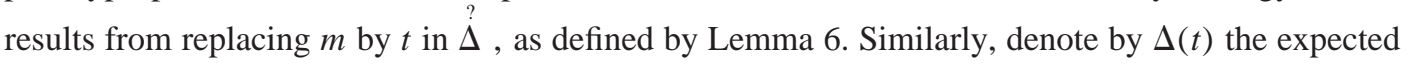
number of periods of mass production if it continues to follow the nursery strategy, which results from replacing $m$ by $t$ in $\Delta$. Thus, the expected profits for this firm over its remaining operating life if it continues to follow the nursery strategy are $\stackrel{?}{\Delta}(t) \stackrel{?}{\pi}_{D}+\Delta(t) \pi_{S}$. If instead this firm relocates to a specialized city where all firms are using a type of process it has not yet tried, and stays there whatever happens, its expected profits over its remaining operating life are

$$
(1-\delta)\left\{?_{\pi_{S}}+(1+\delta)\left[\frac{1}{t} \frac{\pi_{S}}{\delta}+\frac{t-1}{t} \frac{?}{\delta}\right]\right\} .
$$

Using (26) and (31), these are no greater than the expected profits of continuing to follow the nursery strategy if and only if

$$
m^{\varepsilon(\sigma-1)} \leq \frac{t \delta}{(1-\delta)(t-1+\delta)}\left[\stackrel{\Delta}{\Delta}(t)+\left(\Delta(t)-\frac{(1-\delta)^{2}}{t \delta}\right) \frac{1-\mu}{\mu} \Omega\right]
$$

If Conditions 1 and 2 are satisfied, the right-hand side of (B1) is decreasing in $t$ : if a firm is to give up the search for its ideal process, it prefers to do so as early as possible. Hence, we only need to 
check that (B1) is satisfied for $t=m-1$. But, if Condition 1 is satisfied, locating in a diversified city for just one period and then relocating permanently to a specialized city is dominated by permanent location in a specialized city, which is ruled out by Condition 4 . We also show below that Conditions 1 and 3-5 rule out strategies that involve relocating from a specialized to a diversified city. Thus, the only remaining possibility for a firm that relocates from a diversified to a specialized city before finding its ideal process is to relocate across specialized cities until it finds its ideal process, and then engage in mass production. Denote by $\stackrel{?}{\Delta}_{\text {OSC }}(t)$ the expected remaining periods of prototype production if it does this, conditional on remaining in operation after the first relocation, which result from replacing $m$ by $t$ in $\stackrel{?}{\Delta}$ OSC. Similarly, denote by $\Delta_{O S C}(t)$ the expected periods of mass production, which results from replacing $m$ by $t$ in $\Delta_{O S C}$. Thus, the expected profits over its remaining operating life for a firm that relocates from a diversified to a specialized city not yet knowing which of the $t$ processes it has not yet tried is its ideal one, with the intention of finding this by relocating across cities of different specialization, is $(1-\delta)\left[\stackrel{?}{\Delta}_{O S C}(t) \stackrel{?}{\pi}_{S}+\Delta_{O S C}(t) \pi_{S}\right]$. This is not a profitable deviation from the nursery strategy if and only if

$$
(1-\delta)\left[\stackrel{?}{\Delta}_{O S C}(t) \stackrel{?}{\pi}_{S}+\Delta_{O S C}(t) \pi_{S}\right] \leq \stackrel{?}{\Delta}(t) \stackrel{?}{\pi}_{D}+\Delta(t) \pi_{S}
$$

Substituting (26) and (31) into (B2) and rearranging yields

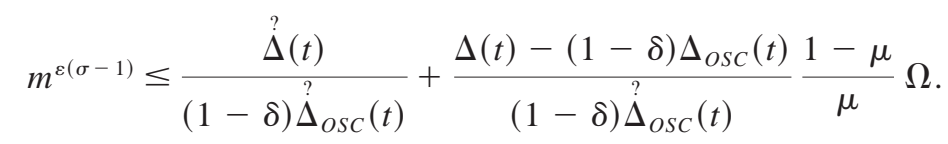

Condition 4 implies $\delta<0.5$. And, with $\delta<0.5$, dependence of the right-hand side of (B3) on $t$ is such that, if it is satisfied for $t=2$ (which is guaranteed by Condition 4) and for $t=m-1$ (which is guaranteed by Condition 5), then it is satisfied for all $2 \leq t \leq m-1$. Thus Conditions 1-5 rule out any deviations involving relocation from a diversified to a specialized city before a firm finds its ideal process.

Let us turn to deviations involving initial location in a specialized city beyond those directly ruled out by Conditions 4 and 5. A firm locating initially in a specialized city could search for its ideal process by relocating across specialized cities for up to its first $t$ prototypes and, if it has not found its ideal process by then and is still in operation, relocate to a diversified city and follow the nursery strategy thereafter. The expected lifetime profits of a firm following this deviation are

$$
\begin{aligned}
& \frac{t}{m}\left(\frac{(1-\delta)\left[1-(1-\delta)^{2 t}\right]}{t(2-\delta) \delta^{2}} \stackrel{?}{\pi}_{S}+\frac{(1+t)(2-\delta) \delta-1+(1-\delta)^{2 t}[1-(2-\delta) \delta]}{t(2-\delta)^{2} \delta^{2}} \pi_{S}\right) \\
& \quad+\frac{m-t}{m}\left(\frac{1-(1-\delta)^{2 t}}{(2-\delta) \delta} \stackrel{?}{\pi}_{S}+(1-\delta)^{2 t}\left(\stackrel{?}{\Delta}(m-t) \stackrel{?}{\pi}_{D}+\Delta(m-t) \pi_{S}\right)\right)
\end{aligned}
$$

With Conditions 1, 4, and 5 satisfied, this expression is no greater than the left-hand side of (36), which in turn is no greater than the expected profits of a firm following the nursery strategy. This is therefore not a profitable deviation.

This brings us back to the deviation mentioned above but not formally discussed, in which a firm follows the nursery strategy for some periods, if unsuccessful continues the search for its ideal process in specialized cities for some periods, and if still unsuccessful comes back to the nursery strategy. The expected profits for such a firm from the point at which it first deviates from the nursery strategy are the result of replacing $m$ in (B4) by the number of processes the firms has not yet tried at that point, replacing $t$ by the number of processes it intends to try if necessary in specialized cities, 
and multiplying the result by $1-\delta$. But, if Conditions 1 and 3-5 are satisfied, this is no greater than the left-hand side of (B2), which in turn we have already shown is no greater than the expected profits of continuing to follow the nursery strategy. So Conditions 1 and 3-5 guarantee that this deviation is not profitable either.

This also eliminates all other deviations involving location in diversified cities after some periods of prototype production in specialized cities. Given the strategy of other firms, the profitability of any strategy only depends on a firm's current location and, if it does not know its ideal process, on how many possibilities there are left. Deviations that result from replacing the nursery strategy for some other strategy after moving from a specialized to a diversified city are therefore covered by the conditions derived so far.

\section{REFERENCES}

Abdel-Rahman, Hesham M. "City Systems: General Equilibrium Approaches," in Jean-Marie Huriot and Jacques-François Thisse, eds., Economics of cities: Theoretical perspectives. Cambridge: Cambridge University Press, 2000, pp. 109-37.

Abdel-Rahman, Hesham and Fujita, Masahisa. "Product Variety, Marshallian Externalities, and City Sizes." Journal of Regional Science, May 1990, 30(2), pp. 165-83.

Arnott, Richard J. and Stiglitz, Joseph E. "Aggregate Land Rents, Expenditure on Public Goods, and Optimal City Size." Quarterly Journal of Economics, November 1979, 93(4), pp. 471-500.

Baldwin, Richard E. and Forslid, Rikard. "Trade Liberalisation and Endogenous Growth: A $q$-Theory Approach." Journal of International Economics, April 2000, 50(2), pp. 497-517.

Becker, Randy and Henderson, J. Vernon. "Intra-industry Specialization and Urban Development," in Jean-Marie Huriot and JacquesFrançois Thisse, eds., Economics of cities: Theoretical perspectives. Cambridge: Cambridge University Press, 2000, pp. 138-66.

Black, Duncan and Henderson, J. Vernon. "Urban Evolution in the U.S." Working Paper No. 98-21, Brown University, August 1998.

Combes, Pierre-Philippe. "Economic Structure and Local Growth: France, 1984-1993." Journal of Urban Economics, May 2000, 47(3), pp. 329-55.

Dumais, Guy; Ellison, Glenn and Glaeser, Edward L. "Geographic Concentration as a Dynamic Process." National Bureau of Economic Research (Cambridge, MA) Working Paper No. 6270, November 1997.
Duranton, Gilles and Puga, Diego. "Diversity and Specialisation in Cities: Why, Where and When Does It Matter?" Urban Studies, March 2000a, 37(3), pp. 533-55.

. "Nursery Cities: Urban Diversity, Process Innovation, and the Life-Cycle of Products." Centre for Economic Policy Research (London) Discussion Paper No. 2376, February $2000 \mathrm{~b}$.

Eaton, Jonathan and Eckstein, Zvi. "Cities and Growth: Theory and Evidence from France and Japan." Regional Science and Urban Economics, August 1997, 27(4-5), pp. 443-74.

Ellison, Glenn and Glaeser, Edward L. "Geographic Concentration in U.S. Manufacturing Industries: A Dartboard Approach." Journal of Political Economy, October 1997, 105(5), pp. 889-927.

. "The Geographic Concentration of Industry: Does Natural Advantage Explain Agglomeration?" American Economic Review, May 1999 (Papers and Proceedings), 89(2), pp. 311-16.

Ethier, Wilfred J. "National and International Returns to Scale in the Modern Theory of International Trade." American Economic Review, June 1982, 72(3), pp. 389-405.

Feldman, Maryann P. and Audretsch, David B. "Innovation in Cities: Science-Based Diversity, Specialization and Localized Competition." European Economic Review, February 1999, 43(2), pp. 409-29.

Flatters, Frank; Henderson, Vernon and Mieszkowski, Peter. "Public Goods, Efficiency, and Regional Fiscal Equalization." Journal of Public Economics, May 1974, 3(2), pp. 99-112.

Fujita, Masahisa. "A Monopolistic Competition Model of Spatial Agglomeration." Regional Science and Urban Economics, February 1988, 18(1), pp. 87-124. 
. Urban economic theory: Land use and city size. Cambridge: Cambridge University Press, 1989.

Fujita, Masahisa and Ishii, Ryoichi. "Global Location Behavior and Organizational Dynamics of Japanese Electronics Firms and Their Impact on Regional Economies," in Alfred D. Chandler, Jr., Peter Hagström, and Örjan Sölvell, eds., The dynamic firm: The role of technology, strategy, organization and regions. Oxford: Oxford University Press, 1998, pp. 343-83.

Fujita, Masahisa and Thisse, Jacques-François. Economics of agglomeration. Cities, industrial location, and regional growth. Cambridge: Cambridge University Press, 2002.

Garreau, Joel. Edge city: Life on the new frontier. New York: Doubleday, 1991.

Glaeser, Edward L.; Kallal, Heidi; Scheinkman, José A. and Schleifer, Andrei. "Growth in Cities." Journal of Political Economy, December 1992, 100(6), pp. 1126-52.

Greenwood, Michael J. "Internal Migration in Developed Countries," in Mark R. Rosenberg and Oded Stark, eds., Handbook of population and family economics, Vol. 1B. Amsterdam: North-Holland, 1997, pp. 647-720.

Harrison, Bennett; Kelley, Maryellen R. and Gant, Jon. "Specialization versus Diversity in Local Economies: The Implications for Innovative Private-Sector Behavior." Cityscape: A Journal of Political Development and Research, May 1996, 2(2), pp. 61-93.

Henderson, J. Vernon. "The Sizes and Types of Cities." American Economic Review, September 1974, 64(4), pp. 640-56.

. "General Equilibrium Modelling of Systems of Cities," in Edwin S. Mills, ed., Handbook of regional and urban economics, Vol. 2. Amsterdam: North-Holland, 1987, pp. 927-56.

. Urban development: Theory, fact and illusion. Oxford: Oxford University Press, 1988.

."Externalities and Industrial Development." Journal of Urban Economics, November 1997a, 42(3), pp. 449-70.

. "Medium Size Cities." Regional Science and Urban Economics, November 1997b, 27(6), pp. 583-612.

. "Marshall's Economies." National Bureau of Economic Research (Cambridge,
MA) Working Paper No. 7358, September 1999.

Henderson, J. Vernon and Becker, Randy. "Political Economy of City Sizes and Formation." Journal of Urban Economics, November 2000, 48(3), pp. 453-84.

Henderson, Vernon; Kuncoro, Ari and Turner, Matt. "Industrial Development in Cities." Journal of Political Economy, October 1995, 103(5), pp. 1067-90.

Henderson, Vernon and Mitra, Arindam. "The New Urban Landscape: Developers and Edge Cities." Regional Science and Urban Economics, December 1996, 26(6), pp. 613-43.

Henderson, J. Vernon and Thisse, JacquesFrançois. "On Strategic Community Development." Journal of Political Economy, June 2001, 109(3), pp. 546-69.

Institut National de la Statistique et des Etudes Economiques (INSEE). Enquête sur la Structure des Emplois (ESE). Paris: INSEE, December 1993. - Système Informatique pour le Répertoire des ENtreprises et de leurs Établissements (SIRENE). Paris: INSEE, 1993-1996. 1998.

Jacobs, Jane. The economy of cities. New York: Random House, 1969.

Jovanovic, Boyan. "Selection and the Evolution of Industry." Econometrica, May 1982, 50(3), pp. 649-70.

Jovanovic, Boyan and MacDonald, Glenn M. "Competitive Diffusion." Journal of Political Economy, February 1994, 102(1), pp. $24-52$.

Kelley, Maryellen R. and Helper, Susan. "Firm Size and Capabilities, Regional Agglomeration, and the Adoption of New Technology." Economics of Innovation and New Technology, 1999, 8(1-2), pp. 79-103.

Kim, Sukkoo. "Expansion of Markets and the Geographic Distribution of Economic Activities: The Trends in U.S. Regional Manufacturing Structure, 1860-1987." Quarterly Journal of Economics, November 1995, 110(4), pp. 881-908.

Lainé, Frédéric. "Mobilité des Établissements et Déconcentration Urbaine," in Denise Pumain and Francis Godard, eds., Données urbaines, Vol. 2. Paris: Anthropos, 1998, pp. 263-72. 
Lainé, Frédéric and Rieu, Carole. "La Diversité Industrielle des Territoires." Institut National de la Statistique et des Etudes Economiques (Paris) Premiere No. 650, June 1999.

Quigley, John M. "Urban Diversity and Economic Growth." Journal of Economic Perspectives, Spring 1998, 12(2), pp. 127-38.

Serck-Hanssen, Jan. "The Optimal Number of Factories in a Spatial Market," in Hendricus C. Bos, ed., Towards balanced international growth. Amsterdam: North-Holland, 1969, pp. 269-82.

Starrett, David A. "Principles of Optimal Location in a Large Homogeneous Area." Journal of Economic Theory, December 1974, 9(4), pp. 418-48.

Stiglitz, Joseph E. "The Theory of Local Public Goods," in Martin S. Feldstein and Robert P. Inman, eds., The economics of public services. London: MacMillan, 1977, pp. 274-333.

Tobin, James. "A General Equilibrium Approach to Monetary Theory." Journal of Money, Credit, and Banking, February 1969, 1(1), pp. 15-29.

Vickrey, William S. "The City as a Firm," in Martin S. Feldstein and Robert P. Inman, eds., The economics of public services. London: MacMillan, 1977, pp. 334-43. 